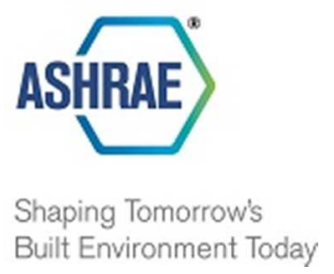

\title{
Moisture induced changes in the building physics parameters of insulation materials
}

\begin{tabular}{|r|l|}
\hline Journal: & ASHRAE \\
\hline Manuscript ID & STBE-00122-2015.R3 \\
\hline Publication: & Science and Technology for the Built Environment \\
\hline Keywords: & $\begin{array}{l}\text { Building Envelope, Insulation, Research \& Development, Testing } \\
\text { Laboratories }\end{array}$ \\
\hline \multicolumn{2}{|l}{} \\
\hline
\end{tabular}

SCHOLARONE ${ }^{m}$

Manuscripts 


\section{Response to Reviewers 3:}

Dear Dr. Reinhard Radermacher,

Editor in chief

Deeply respected Reviewers,

Please find attached the corrected version of my manuscript and if possible, for publication in Science and Technology for the Built Environment.

Dear Reviewer,

Thank you very much for your work, the English of the paper was carefully checked and corrected by a native speaker.

Dear Editor and Reviewers,

now I hope you could accept my answers and you could recommend my re-re-revised paper for publication.

Many thanks and the very best regards,

Yours sincerely,

the author

Review Copy Only. Not for distribution. 


\title{
Moisture induced changes in the building physics parameters of insulation materials
}

Keywords: Building envelope, Insulation, Research and development, Testing Laboratories

\begin{abstract}
In recent years measurements and calculations of the thermal properties of building physics parameters of materials have become very important for thermal sizing and designing buildings. Moisture is an essential factor to consider when designing and applying building materials. This paper investigates the influence of moisture in the building physical properties of insulating materials. Thermal insulating of buildings is sorely needed regarding energy as well as saving money. This article presents calculations for the changes in the most important building physics parameters of insulation materials influenced by water after measuring their thermal conductivity, moisture content and density. Furthermore, this article will also present the positive or negative effects of water. Three different types of polystyrene (expanded, graphite doped expanded, extruded), mineral- and glass-wool fibers as well as gypsum boards were tested. The non-equilibrium sorption behavior of the expanded polystyrene materials was achieved in a type Climacell 111 climatic chamber after drying them in a type Venticell 111 desiccating apparatus. The relative humidity varied from $25 \%$ to $90 \%$ at $293 \mathrm{~K}$ for 240 min. The thermal conductivity of each sample was determined by using a Holometrix 2000 (HLS) heat flow meter after drying the samples to changeless weight in the above mentioned desiccating apparatus.
\end{abstract}

\section{Introduction}

Nowadays, insulating buildings is highly important in order to save energy and to minimize the emission of greenhouse gases. Furthermore, several types of insulation materials are available that differ concerning their thermal properties, their material properties and their 
costs (e.g.: Silica aerogel, Poly-urethane slab, vacuum panels etc.). Concerning energy efficiency, the main properties of insulating materials are the thermal conductivity, specific heat and bulk density. In order to calculate the thermal performance of structures these values are used to design building walls and roofs. Thus the main aim of this article is the comparison and presentation of the 6 thermal insulators mainly used: pure white and graphite enhanced expanded polystyrene, extruded polystyrene, mineral- and glass-wool as well as gypsum-board. Materials exposed to variations in the surrounding climate will absorb moisture when the relative humidity increases. (Gnip et al, 2006, Karoglu et al, 2005, Lakatos and Kalmár 2013a, 2014, Lakatos, 2011, 2014b, Papadopoulus, 2005, Stubberud, 1994, Vejelis, 2006, Velasco et al, 2014, 2015) The response is - to a large extent - due to the material composition, structure and surface. If building materials get in contact with indoor air they have some effects on moderating the variations of indoor humidity in occupied buildings. However, there has not been a well defined, standardized quantity to characterize the moisture buffering capability of materials so far. In this paper, calculations - based on measurement results - of the moisture induced variations in thermal conductivity, bulk density, specific heat capacity, thermal diffusion and resistance, time lag, heat absorption and in thermal inertia are presented. Therefore the thermal conductivities of the materials were measured in laboratory by Holometrix 2000 series Heat Flow Meter; furthermore; the initial state sorption behavior was investigated by the combination of Venticell 111 and Climacell 111 with a milligram preciseness balance. (Ajlan, 2006, Al-Homoud, 2005, Lakatos, 2014a, Lakatos and Kalmár 2013a,b, Morales et al, 2011, Shanshan et al, 2012, 2014 ). The expanded polystyrene (EPS) materials are proved to be reasonable insulators, since by using them relatively high efficiency could be reached (e.g. EPS 200 or graphite doped ones), moreover they have relatively low price. They are mainly used as frontage insulators. The reason for this can be found in the following: their capability to take up water does not allow their use at plinth because of their open cells; besides, these cells can fill up with water easily and can decrease the thermal efficiency, therefore they can destroy the building structure (except for the one with very high density). (Lakatos, 2014a, Lakatos and Kalmár, 2013a). The fibrous (mineralwool, glass-wool) ones can be used at frontage as well as on roofs. Their filamentous structure does not allow us to use them as baseboard, because their structure allows permeability of air. The extruded polystyrene (XPS) with its closed cells can be used as plinth insulating. Therefore these cells cannot be filled up easily with water. They are not only thermal but water insulators as well (Lakatos, 2014a, Lakatos and Kalmár, 2013a). Gypsum-boards are 
used for decoration and sound insulation as well as fire-safety rather than thermal insulation. (Al-Ajlan, 2006).

\section{Practical HVAC applications}

The moisture has effect on several factors used in indoor environment e.g.: on mean radiant temperature, by changing the thermal conductivity of the wall, as well as on the indoor humidity, by changing the indoor air quality. If moisture diffuses from the structure, it may result in surface condensation in case the temperature of the surface is below the dew point temperature of humidity. Humidity should be controlled inside the building by passive ventilation, by opening windows for cross ventilation furthermore by removing moisture at source, for example, using an extract fan in the bathroom, using a range hood in the kitchen, venting a dryer to the outside and using only externally vented gas heaters raising indoor temperatures by heating or insulating, since warmer temperatures imply lower relative humidity. High moisture load will require the change of the above mentioned methods. Moisture is a common cause of building degradations-. In fact, much of what we know about applied building science today originates from early work that investigates moisture impact on buildings. While the severity of moisture problems varies greatly depending on climate, few regions in North America are free from concerns about moisture in buildings. These estimations that are based on the laboratory measurements of these values of the insulating materials are very important both for the manufacturers and the contractors, planners and designers.

\section{Materials and methods}

Both the sorption and the thermal conductivity measurements were carried out after drying the samples in a VentiCell drying instrument. Materials can be dried with this device by setting different air temperatures (up to $523 \mathrm{~K}$ ). It works with hot air circulation using an inbuilt ventilator (Lakatos 2011, 2014a, Lakatos and Kalmár 2013, a,b, Shansan, 2014, Velasco et al, 2015). The sorption measurements were executed according to the ISO 12571:2013 standard. According to this standard the minimal wetting time is 24 hours to reach the equilibrium state. In my opinion and in reality the relative humidity is one of the rapidly changing parameters in time. 240 min wetting time was chosen for the materials to reach a moisture content that can be measured and to provide a base for the estimations, calculations. For wetting further (in time) the materials should take up more water till they reach the equilibrium state. Based on our previous measurements and papers after 240 min wetting the materials reach a measurable amount of water that can have harmful effects. (Lakatos 2011, 2014a, Lakatos and Kalmár 
2013, a) In this article it was not aimed to reach the equilibrium state; nevertheless, it could be the basis for other and further investigations. Both for the non-equilibrium sorption and for the thermal conductivity measurements three samples with $30 \mathrm{~cm}$ x $30 \mathrm{~cm}$ x $5 \mathrm{~cm}$ geometries were prepared from the original pieces in order to perform the measurements on three specimens from the same material. The results were obtained by averaging the results of three measurements. Before treating the samples in the CLC climatic chamber, samples were dried to changeless weight at $343 \mathrm{~K}$ under normal atmospheric pressure $\left(10^{5} \mathrm{~Pa}\right)$ at all times. This temperature was chosen because it is fairly below the melting point of the materials (about $373 \mathrm{~K}$ ) and during the dehydrating process at this temperature the materials do not suffer any losses in their physical and chemical properties. To determine the initial state sorption data (moisture content of material in function of relative humidity (RH \%) of air at $293 \mathrm{~K}$ ) the samples were kept in the CLC chamber under 25, 45, 60, 75 and $90 \% \mathrm{RH}$ for 240 minutes. The water/moisture content ( $\omega \%$ ) of a solid material can be calculated from the next simple equation (Eq. 1):

$$
\omega=\frac{m_{w}-m_{d}}{m_{d}}
$$

where $m_{d}$ and $m_{w}$ are the mass of the dried and the damped samples respectively. For measuring the thermal conductivity of each polystyrene sample, Lambda 2000 Heat flow meter (HFM) was used. This equipment is designed to determine the thermal conductivity of insulation materials in accordance with standard ASTM C518 and ISO 8301 protocols. A sample with $30 \mathrm{~cm} \times 30 \mathrm{~cm} \times 5 \mathrm{~cm}$ geometry is placed in the test section between two plates which are maintained at different temperatures $\left(T_{1}=285 \mathrm{~K}\right.$ and $T_{2}=295 \mathrm{~K}$, with $\left.T_{\text {mean }}=290 \mathrm{~K}\right)$ during the test. After achieving thermal equilibrium and establishing a uniform temperature gradient throughout the sample the thermal conductivity is determined. To reach the thermal conductivity of a sample, three independent measurements were carried out. The thermal conductivity of the analyzed material was the mean value of the three measured results as above mentioned. For the thermal conductivity measurements the MSZ ISO 8301 standard was followed. In order to understand the measurement method of Holometrix Lambda 2000 Heat Flow Meter (HFM) equipment, the following observations are indispensable. The magnitude of the heat flux (q) depends on several factors, including:

-thermal conductivity of samples $(\lambda=\mathrm{k})$

-thickness of the specimen $(\Delta x)$

-temperature difference across the specimen $(\Delta \mathrm{T})$ 
-area through which the heat flows (A).

The Fourier heat flow equation (Eq. 2.) gives the relationship between these parameters when the test section reaches thermal equilibrium.

$q=\lambda A \frac{\Delta T}{\Delta x}$

One or two heat flow transducers measure the heat flow through the specimen. The signal of a heat flow transducer (in Volts $(\mathrm{U})$ ) is proportional to the heat flow through the transducer. In the instrument mentioned above, the area of the heat flow transducer represents the area through which the heat conduction is realized and it is the same for all specimens, therefore the heat flow will be (Eq. 3):

$q=N U$

Where $\mathrm{N}$ is the calibration factor that relates the voltage signal of the heat flow transducer to the heat flux through the specimen. For the calibration of apparatus a fibrous glass board standard sample with $\lambda=0.038 \mathrm{~W} / \mathrm{mK}$ was used. Using Eq. 2 and Eq. 3 the heat conductivity can be found (Eq. 4):

$$
\lambda=k=N \frac{U \Delta x}{\Delta T}
$$

The term reproducibility indicates the variation of the test results of one specimen from test to test. Factors such as how well the specimen makes contact with the plates and the temperature stability affect the reproducibility. If the thermal resistance of the test specimen is commensurable with the reference standard, $\pm 5 \%$ or better accuracy can be obtained. (Lakatos 2011, 2014a, Lakatos and Kalmár 2013, a,b, Shansan 2014, Velasco et al, 2015)

\section{Calculations of the wet properties}

\subsection{Bulk Density}

The density or more precisely, the volumetric mass density of a substance is its mass per unit volume. The symbol most often used for density is $\rho$ (the lower case Greek letter rho). Mathematically density is defined as mass divided by volume. (Web Reference 1) The bulk density of the wet samples $\left(\rho_{\mathrm{w}}\right)$ can be defined as the mass of the wet samples in the given volume.

$\rho_{w}=\frac{m_{w}}{V}$ 
By taking into account the moisture content and the density of the dry samples $\left(\rho_{d}\right)$ :

$$
\rho_{w}=\frac{\omega}{100} \rho_{d}+\rho_{d}
$$

\subsection{Specific heat capacity}

Heat capacity or thermal capacity is a measurable physical quantity equal to the ratio of the heat added to (or removed from) an object to the resulting temperature change. (Web Reference 1) The specific heat capacity of the wet samples can be calculated as the following:

$c_{w}=\frac{c_{d} \times(100-\omega)+c_{\text {water }} \times \omega}{100}$

where $c_{d}, c_{w}$ and $c_{w a t e r}$ are the specific heat capacities of the dry sample, the wet sample and the water respectively. (Fekete, 1985)

\subsection{Thermal conductivity}

It is the ability of a material to conduct heat. Each material has a characteristic rate at which heat will flow through it. The faster heat flows through a material, the more conductive it is. Conductivity $(\lambda)$ is a material property given for homogeneous solids under steady state conditions. (Web Reference 1) The thermal conductivity of the wet samples can be calculated as the function of water content $(\omega)$ and by knowing $\mathrm{Z}$ which is a helping constant (for plastic foam and mineral wool samples $Z=2$ ) and the measured dry thermal conductivity $\lambda_{\mathrm{d}}$ :

$\lambda_{w}=\lambda_{d} \times\left(1+\frac{\omega \times Z}{100}\right)$

It can be seen in these references also: (Lakatos and Kalmár, 2013a, 2014, (Fekete, 1985).

\subsection{Thermal diffusion coefficient}

In heat transfer analysis thermal diffusivity is the thermal conductivity divided by density and specific heat capacity at constant pressure. It measures the ability of a material to conduct thermal energy relative to its ability to store thermal energy. Thermal diffusivity is usually 
denoted $\alpha$ but $\mathrm{D}$ is also used. The thermal diffusion coefficient of the wet materials can be calculated as a basis of the thermal conductivity, specific heat and density of the wet samples

$D_{T w}=\frac{\lambda_{w}}{\rho_{w} c_{w}}$

(Lakatos, 2014a, Lakatos et al, 2015)

\subsection{Time lag}

With high thermal mass it can take hours for heat to flow from one side of the envelope to the other. This slowing of the flow of heat is called "thermal lag" (or time lag), and is measured as the time difference between peak temperature on the outside surface of a building element and the peak temperature on the inside surface. Some materials like glass do not have much of a thermal lag. However, the thermal lag can be as long as eight or nine hours for constructions with high thermal mass like double-brick or rammed earth walls. (Web Reference 1) The time lag of a wet one- or multi-layered structure can be estimated easily by using the Eq. 10

$t_{w}=\frac{d^{2}}{4 \times D_{T_{w}} \times 3600}$

Here for the $\mathrm{d}$ (thickness) $0.1 \mathrm{~m}$ was chosen except the gypsum board where 0.0125 was used for the thickness. (Lakatos, 2014a, Lakatos et al, 2015)

\subsection{Thermal resistance}

Thermal resistance is the ability of a material to resist heat flow. Designated as R (R-value), thermal resistance indicates how effective any material is as an insulator. The reciprocal of thermal conductance, $\mathrm{R}$ is measured in seconds needed for $1 \mathrm{~J}$ to flow through $1 \mathrm{~m}^{2}$ of a given thickness of a material when the temperature difference is $1^{\circ} \mathrm{K}$. In the Imperial system, the unit is $\mathrm{m}^{2} \mathrm{~K} / \mathrm{W}$. (Web Reference 1) The thermal resistance of the wet layer can be calculated by dividing the thickness of the layer with the wet thermal conductivity.

$$
R_{w}=\frac{d}{\lambda_{w}}
$$

\subsection{Heat absorption and thermal inertia}


The heat absorption of the wet layer $\left(b_{\mathrm{w}}\right)$ can be calculated as the square root of the multiplication of thermal conductivity, density and specific heat capacity of the wet sample, (Fekete, 1985):

$$
b_{w}=\sqrt{\lambda_{w} \times \rho_{w} \times c_{w}}
$$

The thermal inertia of a material is the multiplication of its resistance and heat absorption coefficient. The thermal inertia of a wet sample can be calculated the same way but we have to substitute it with the wet values. (Fekete, 1985) The resistance of a material to temperature change is indicated by the time dependent variations in temperature during a full heating/cooling cycle (a 24-hour day for Earth). This parameter governs the rate of temperature change within a material; it is a measure of a substance's ability to transfer heat in and out of the portion that receives solar heating during the day and cools at night. This is a measure of the heat transfer rate across a boundary between two materials. e.g., air/soil. Since materials with high value possess a strong inertial resistance to temperature fluctuations at surface boundaries they show less temperature variation per heating/cooling cycle than those with lower thermal inertia. (Web Reference 1)

$$
D_{w}=R_{w} \times b_{w}
$$

\section{Results and discussion}

\subsection{Measurement results}

In this section the paper would present the effects of moisture load on the indoor environment and the building structure of buildings. Moisture can get into the building's structure since it can diffuse to the indoor environment. It is clearly written in our previous papers. The high indoor humidity causes indoor condensation problems. (Lakatos A, 2011, 2014 b, Lakatos and Kalmár 2013 a)

Herewith we present measured thermal conductivities in Figure 1 and the sorped amount of water in Table 1. In Figure 1 the measured thermal conductivities that are analysed with box chart method can be found. For investigating the deviances and the mean values the box chart method was used. On the graph we can see that gypsum-board has higher thermal conductivity than the other insulation materials, however, the lowest value belongs to EPS 200 and the graphite doped ones. The thermal conductivity of XPS and mineral wool is about in the same order, moreover, the value of glass-fiber falls between the values of these four insulations. 
In Table 1 we can see the measured amount of the sorped water. We can observe that the gypsum-board takes up the most, followed by the glass-fiber and the graphite doped one. The XPS takes up the least amount of water, furthermore, the water permeability of EPS 200 and mineral-wool is also acceptable. Here it has to be emphasized that only the procession of the data of gypsum boards jumps out from the otrhers. Furthermore it has to be mentioned that gypsum board is slightly hygroscopic. With reference to our recent and previous articles and measurements, for this type of moisture investigation (climatic chamber method) maximum $\pm 5 \%$ error can be taken into account for the result values. (Lakatos and Kalmár 2013a, 2014, Lakatos, 2011)

\subsection{Calculations based on the measurement results}

\subsubsection{Bulk density}

In Table 2 and in Figure 2 the function of bulk density in function of relative humidity, as a result of the moisture content can be seen. The values that belong to $0 \%$ relative humidity are the measured dry bulk densities. As it is showed, a slight increase in the density of all materials is expected by using Eq. 5 and 6 . Here it should be noted that the plotted graphs are nearly parallel, however, when the RH is higher than $75 \%$, a weak jump/ can be observed on the bulk density of the insulation materials according to the values reported in Table 2 . The effect of the moisture on the density can be accepted as a beneficent phenomenon, as the thermal mass of the materials can be increased by moisture.

\subsubsection{Specific heat capacity}

In Figure 3 the increase in the specific heat capacity reached by using Eq. 7 for all materials can be observed. The dry specific heat capacity values were taken from (Fekete I et al., 1985). We can observe a great jump in this property after $65 \%$ relative humidity that belongs to the glass-, mineral-wool and to the gypsum boards. This increasing behavior is caused by the absorbed quantity of the water of these materials. After $65 \%$ much higher moisture content is observable. The increase in the specific heat capacity of the polystyrene materials is negligible. The increase can be good for the materials because greater specific heat results greater thermal mass of the building and time constant for the rooms.

\subsubsection{Thermal conductivity and thermal resistance}

In this section we will see the harmful effects of the sorped amount of water. Thermal conductivity and thermal resistance can be managed together caused by their definition. By 
using Eq. 8 and 11 from the measured thermal conductivities we can predict the change in these values influenced by water. The change in thermal conductivities shows a slight increase for all materials that result in a decrease in their resistance. From Figure 4 and 5 we can see that the greatest change belongs to gypsum boards and to graphite doped EPS. For the graphite doped one the thermal conductivity change is nearly the double of its original value. The thermal conductivity of the fiberglass remains approximately around a constant after $25 \%$ relative humidity, however considerable jump can be found under this relative humidity. In the thermal conductivity of the gypsum boards one can see a nearly linear increase and in the resistance its contradistinction can be seen. The behavior of other materials is nearly the same. (Lakatos and Kalmár, 2013a) An initial jump followed by a plateau and an increase was shown by the calculations on the thermal conductivity graphs of the other materials. The increase of thermal conductivity is the most sensitive part of this article. Since an increase in the thermal conductivity of the elements of the wall structures can increase the heat flow, the heat loss, the heating energy demand, therefore the heating costs as well.

\subsubsection{Thermal diffusion coefficient and time lag}

Similarly to the previous section thermal diffusion and time lag can be managed together because of their relationship. The thermal diffusion coefficient is computed by using Eq. 7, furthermore the time lag is computed from this value. From Figures 6 and 7 we can see that the materials can be divided into two groups. The first group is where the thermal diffusion coefficient of the materials increases by the function of the moisture content, since their time lag is decreasing.. From Figures 6-7 we can see the increasing thermal diffusion coefficient and the decreasing time lag of the graphite doped EPS, EPS 200 and XPS. Thus in case the time lag (delay time) is decreasing faster heat transfer (conduction) as well as greater heat flow and heat loss are expected. It is harmful in any cases. Fibrous materials and the gypsum boards show the opposite behavior (these are in the second group). Their thermal diffusion is decreasing since their time lag is increasing. This behavior is caused by the different degrees of the changes in the specific heat of the materials. If we go back to Figure 3 and take into account Eq. 9 we will observe that the great increase in the specific heat of the two fibrous and the gypsum materials is responsible for this difference, however their thermal conductivity is still increasing. Here it has to be mentioned that higher time lag means better insulation. As a result we can state here that the increasing water content has a positive effect on these materials by increasing their time lag. Moreover for the plastic foams water influenced higher thermal diffusion coefficient means lower thermal resistance and efficiency. 


\subsubsection{Thermal inertia and heat absorption}

In general, thermal inertia and heat absorption come up for floors, however, the insulation of the floor (thermal and also moisture insulation) is an important action as well. From Figure 8 we can see that heat absorption is increasing with increasing moisture content for all the materials. As previously discussed gypsum boards are moisture sensitive, for this material from Figure 8 we can deduce that heat absorption is increasing with increasing moisture content. Furthermore it can be noticed that the heat absorption of the fiberglass and the graphite doped EPS shows distinct increase as well. From Figure 9 we can observe that the thermal inertia of fiberglass increases stepwise and significantly, however, the shape of gypsum boards follows continuous rise. The thermal inertia of mineral wool remains constant, however the other's decrease. Longer inertia means better insulation as a result of the longer heating up and cooling down time, longer discharging and loading time.

\subsubsection{Overall effect of the moisture}

In Table 3 the positive or negative effect of the moisture on the properties of the insulation materials are presented. In the Table "+" means that the moisture influenced change in the property could be good, "“" means that the change in the property of the material could be harmful. As presented in Table 3 we can observe that the specific heat capacity, density and heat absorption are increasing with increasing moisture content. This change is has a beneficent effect because higher specific heat capacity and higher heat absorption results in higher thermal mass and higher time constant and for some materials higher time lag. Thermal mass reduces heat gain in the structure by delaying the heat inlet in the building (until the sun has set).

From Table 3 we can see that regarding thermal conductivity and thermal resistance the increased moisture content has harmful effect. By increasing thermal conductivity the thermal performance of the building will be reduced. Concerning polystyrene insulations we can conclude that moisture has negative effect because it reduces its thermal diffusion, time lag and thermal inertia. However, increasing moisture content results in an increase (positive effect) in the thermal diffusion, time lag and thermal inertia of the gypsum boards, mineraland glass-wool.

\section{Conclusions}


The main goal of this paper is to present an overview of the basic principles of thermal insulation and to survey the most commonly used building insulation materials and the characteristics of their performance. In this comparative research article moisture induced changes in thermo physical properties are presented based on measurement results.

Moisture transfers into the building structure from many sources. If enough quantity of moisture accumulates in the building envelope and it cannot escape, it becomes a good environment for mold, mildew and other moisture-related problems. Different materials have different moisture storage capacity which is a function of time, temperature, and material properties (e.g.: structure). If moisture penetrates into building thermal insulation it will cause physical damage in the building envelope and will adversely affect its insulating performance by increasing its thermal conductivity. Thermal conductivity and non-equilibrium sorption behavior of six different insulation materials were achieved in laboratory environment. Three types of polystyrene (EPS 200, XPS, graphite doped EPS), two types of wool samples (glass and mineral) and gypsum boards were tested. Based on measured bulk density, thermal conductivity and water content calculations were carried out to estimate the influence of moisture in thermal resistance, thermal diffusion, time lag, heat absorption, specific heat capacity and thermal inertia. Moisture has positive effect (increase) on specific heat capacity, density and on heat absorption, while it has negative effects on thermal conductivity and on thermal resistance; moreover it has partially positive and partially negative effect on other properties. We can conclude that water is harmful and it has negative effects on the properties of polystyrene materials. For the wool samples and for the gypsum boards some positive effects were detected e.g.: increasing time lag, and thermal inertia.

\section{Nomenclature}

$\omega$ : moisture content $(\%)$

rh: relative humidity (\%)

$\mathrm{m}_{\mathrm{d}}$ : the mass of the dried sample $(\mathrm{g})$

$\mathrm{m}_{\mathrm{w}}$ the mass of the wet sample $(\mathrm{g})$

index d: dry value

index w: wet value

index water: value of the water

$\mathrm{T}$ : temperature $(\mathrm{K})$

q: heat flux $\left(\mathrm{W} / \mathrm{m}^{2} \mathrm{~K}\right)$

$\lambda=\mathrm{k}$ : thermal conductivity $(\mathrm{W} / \mathrm{mK})$

$\Delta \mathrm{x}=\mathrm{d}$ : thickness $(\mathrm{m})$ 

A: area $\left(\mathrm{m}^{2}\right)$
$\mathrm{N}$ : calibration number for the Holometrix
$\mathrm{U}$ : volts
$\rho:$ density $\left(\mathrm{kg} / \mathrm{m}^{3}\right)$
$\mathrm{V}$ : volume $\left(\mathrm{m}^{3}\right)$
c: specific heat capacity
$\mathrm{D}_{\mathrm{T}}$ : thermal diffusion coefficient $(\mathrm{m} 2 / \mathrm{s})$
$\mathrm{R}$ : resistance $\left(\mathrm{m}^{2} \mathrm{~K} / \mathrm{W}\right)$
b: heat absorption $\left(\mathrm{J} / \mathrm{Km}^{2} \mathrm{~s}^{1 / 2}\right)$
D: thermal inertia $\left(\mathrm{s}^{1 / 2}\right)$

\section{References}

Al-Ajlan S. A. 2006. Measurements of thermal properties of insulation materials by using transient plane source technique. Appl Thermal Eng 26:2184-2191

Al-Homoud M. S.: 2005Performance characteristics and practical applications of common building thermal insulation materials. Build Environ; 40(3): 353-366.

Fekete I. (edited) 1985 Épületfizika kézikönyv. Handbook of Building Physics, Müszaki Könyvkiadó, Publisher of Technical Books, Budapest, ISBN:963 10642 X

Gnip IY, Kersulis V, Vejelis S. 2006. Water absorption of expanded polystyrene boards. Polym Test; 25: 635-641.

Karoglou, M., Moropoulou, A., Maroulis, Z:B, and Krokida, M.K. 2005. Water sorption isotherms of some building materials, Drying Technology, 23:289-303,

Lakatos. A 2011. Method for the determination of sorption isotherms of materials demonstrated through soil samples. Int Rev Appl Sci Eng; 2(2): 117-121.

Lakatos. 2014a.A Comparison of the Thermal Properties of Different Insulating Materials. Advanced Materials Research. 899. 381-386.

Lakatos A. 2014b Investigation Of The Effect Of Moisture In The Time Lag Of Building Walls With Different Insulating Materials. Environmental Engineering And Management Journal 13:(11) Pp. 2853-2858.

Lakatos A, Kalmár F. (2013a) Analysis of water sorption and thermal conductivity of expanded polystyrene insulation materials, Building Services Engineering Research And Technology Vol 34. Issue 4. 407-416. 
Lakatos A, Kalmár F. 2013b Investigation Of Thickness And Density Dependence Of Thermal Conductivity Of Expanded Polystyrene Insulation Materials. Materials and Structures. 46:1101-1105

Lakatos A, Kalmár F. 2014. Examination of the change of the overall heat transfer coefficients of building structures in function of water content. Building Services Engineering Research \& Technology 35:(507) pp. 508-515.

Lakatos A, Csáky I, Kalmar F. 2015. Thermal conductivity measurements with different methods: a procedure for the estimation of the retardation time, Materials and Structures, 48, 5, 1343-1353.

Morales MP, Jua'rez MC, Muñz P, Go'mez JA 2011 Study of the geometry of a voided clay brick using non-rectangular perforations to optimise its thermal properties. Energy Build 43:2494-2498

Papadopoulos A. M.. 2005State of the art in thermal insulation materials and aims for future developments.. Energy Build; 37(1): 77-86.

Sadauskiene J, Bliudzius R, Ramanauskas J 2009. Analysis of distribution of properties of expanded polystyrene in production and their changes in exploitation conditions. Mater Sci; 15(4). ISSN 1392-1320.

Shanshan C.; Cremaschi L., Afshin J. G. 2012. "Moisture Accumulation and Its Impact on the Thermal Performance of Pipe Insulation for Chilled Water Pipes in High Performance Buildings". International High Performance Buildings Conference. Paper 59.

Shanshan C.; Cremaschi L., Afshin J. G., 2014. Pipe insulation thermal conductivity under dry and wet condensing conditions with moisture ingress: A critical review $H V A C \& R$ Research Volume 20, Issue 4,

Stubberud, L., Arwidsson, G. H., Graffner, C. 1994. Water-solid interactions: I. A technique for studying moisture sorption/desorption, International Journal of Pharmaceutics. 114:55-64

Velasco M.P., Mendívil M.A, Morales Ortiz M.P., Velasco M.L. 2015. Eco-fired clay bricks made by adding spent coffee grounds: a sustainable way to improve buildings insulation Materials and Structures, DOI 10.1617/s11527-015-0525-6

Velasco M.P., Mendívil M.A, Morales Ortiz M.P., Velasco M.L 2014 Fired clay bricks manufactured by adding wastes as sustainable construction material—a review. Constr Build Mater 63:97-107

Vejelis S and Vaitkus S. Investigation of water absorption by expanded polystyrene slabs. 2006 Mater Sci Medz iagotyra) 12(2): 134-137 
Web Reference 1: http://sustainabilityworkshop.autodesk.com/buildings/thermal-propertiesmaterials\#sthash.5Cz7GigK.dpuf

1

2

3

4

5

6

7

8

9

10

11

12

13

14

15

16

17

18

19

20

21

22

23

24

25

26

27

28

29

30

31

32

33

34

35

36

37

38

39

40

41

42

43

44

45

46

47

48

49

50

51

52

53

54

55

56

57

58

59

60

Review Copy Only. Not for distribution. 
Tables

Table 1. The measured moisture content in function of relative humidity, with maximum $\pm 5 \%$ accuracy

\begin{tabular}{|r|c|c|c|c|c|c|}
\hline $\begin{array}{c}\text { RH } \\
(\%)\end{array}$ & $\begin{array}{c}\text { EPS200 } \\
(\mathbf{g} / \mathbf{g} \%)\end{array}$ & $\begin{array}{c}\text { G-EPS } \\
\mathbf{( g / g} \%)\end{array}$ & $\begin{array}{c}\text { XPS } \\
(\mathbf{g} / \mathbf{g} \%)\end{array}$ & $\begin{array}{c}\text { Gypsum-board } \\
\mathbf{( g / g} \%)\end{array}$ & $\begin{array}{c}\text { Mineral-wool } \\
\mathbf{( g / g} / \mathbf{g})\end{array}$ & $\begin{array}{c}\text { Glass-fiber } \\
\mathbf{( g / g} / \mathbf{g})\end{array}$ \\
\hline 0 & 0.000 & 0.000 & 0.000 & 0.000 & 0.000 & 0.000 \\
\hline 25 & 0.5 & 0.934 & 0.108 & 0.512 & 0.294 & 0.661 \\
\hline 45 & 0.53 & 0.928 & 0.112 & 0.895 & 0.326 & 0.777 \\
\hline 60 & 0.54 & 0.852 & 0.102 & 1.158 & 0.459 & 1.913 \\
\hline 75 & 0.57 & 0.966 & 0.148 & 1.78 & 0.800 & 1.788 \\
\hline 90 & 0.69 & 1.398 & 0.381 & 3.093 & & \\
\hline
\end{tabular}

Table 2. The calculated change in the bulk density of the materials in function of the relative humidity

\begin{tabular}{|c|c|c|c|c|c|c|}
\hline Rh \% & $\begin{array}{l}\text { EPS200 } \\
\left(\mathrm{kg} / \mathrm{m}^{3}\right)\end{array}$ & $\begin{array}{c}\text { G-EPS } \\
\left(\mathrm{kg} / \mathrm{m}^{3}\right)\end{array}$ & $\begin{array}{c}\text { XPS } \\
\left(\mathrm{kg} / \mathrm{m}^{3}\right)\end{array}$ & $\begin{array}{c}\text { Gypsum-board } \\
\left(\mathrm{kg} / \mathrm{m}^{3}\right)\end{array}$ & $\begin{array}{c}\text { Mineral-wool } \\
\left(\mathrm{kg} / \mathrm{m}^{3}\right)\end{array}$ & $\begin{array}{c}\text { Glass-fiber } \\
\left(\mathrm{kg} / \mathrm{m}^{3}\right)\end{array}$ \\
\hline 0 & $27.500 \pm 0.135$ & $13.660 \pm 0.12$ & $39.710 \pm 0.03$ & $696.880 \pm 0.9$ & $39.670 \pm 0.5$ & $159.995 \pm 0.8$ \\
\hline 25 & 27.638 & 13.788 & 39.753 & 700.448 & 39.787 & 161.053 \\
\hline 45 & 27.646 & 13.787 & 39.754 & 703.117 & 39.799 & 161.238 \\
\hline 60 & 27.649 & 13.776 & 39.751 & 704.950 & 39.806 & 161.456 \\
\hline 75 & 27.657 & 13.792 & 39.769 & 709.284 & 39.852 & 161.910 \\
\hline 90 & 27.690 & 13.851 & 39.861 & 718.434 & 39.987 & 162.856 \\
\hline
\end{tabular}

Table 3. The positive (+) or negative (-) effect of the moisture in the property of the material

\begin{tabular}{|c|c|c|c|c|c|c|c|}
\hline & $\begin{array}{c}\text { Specific heat } \\
\text { capacity }\end{array}$ & $\begin{array}{c}\text { Thermal } \\
\text { conductivity }\end{array}$ & $\begin{array}{c}\text { Thermal } \\
\text { diffusion }\end{array}$ & $\begin{array}{c}\text { Time } \\
\text { lag }\end{array}$ & $\begin{array}{c}\text { Thermal } \\
\text { resistance }\end{array}$ & $\begin{array}{c}\text { Heat } \\
\text { absorption }\end{array}$ & $\begin{array}{c}\text { Thermal } \\
\text { inertia }\end{array}$ \\
\hline EPS200 & + & - & - & - & - & + & - \\
\hline G-EPS & + & - & - & - & - & + & - \\
\hline XPS & + & - & - & - & - & + & - \\
\hline $\begin{array}{c}\text { Gypsum- } \\
\text { board }\end{array}$ & + & - & + & + & - & + & + \\
\hline $\begin{array}{c}\text { Mineral- } \\
\text { wool }\end{array}$ & + & - & + & + & - & + & + \\
\hline Glass-fiber & + & - & + & + & - & + & + \\
\hline
\end{tabular}


Figure captions

1. The measured thermal conductivities plotted by box chart method

2. The moisture influenced changes of the density

3. The moisture influenced changes of the specific heat

4. The moisture influenced changes of the thermal conductivity

5. The moisture influenced changes of the thermal resistance

6. The moisture influenced changes of the thermal diffusion coefficients

7. The moisture influenced changes of the time lag

8. The moisture influenced changes of the heat absorption

9. The moisture influenced changes of the thermal inertia

Table titles:

1. The measured moisture content in function of relative humidity

2. The calculated change in the bulk density of the materials in function of the relative humidity

3. The positive $(+)$ or negative $(-)$ effect of the moisture in the property of the material 


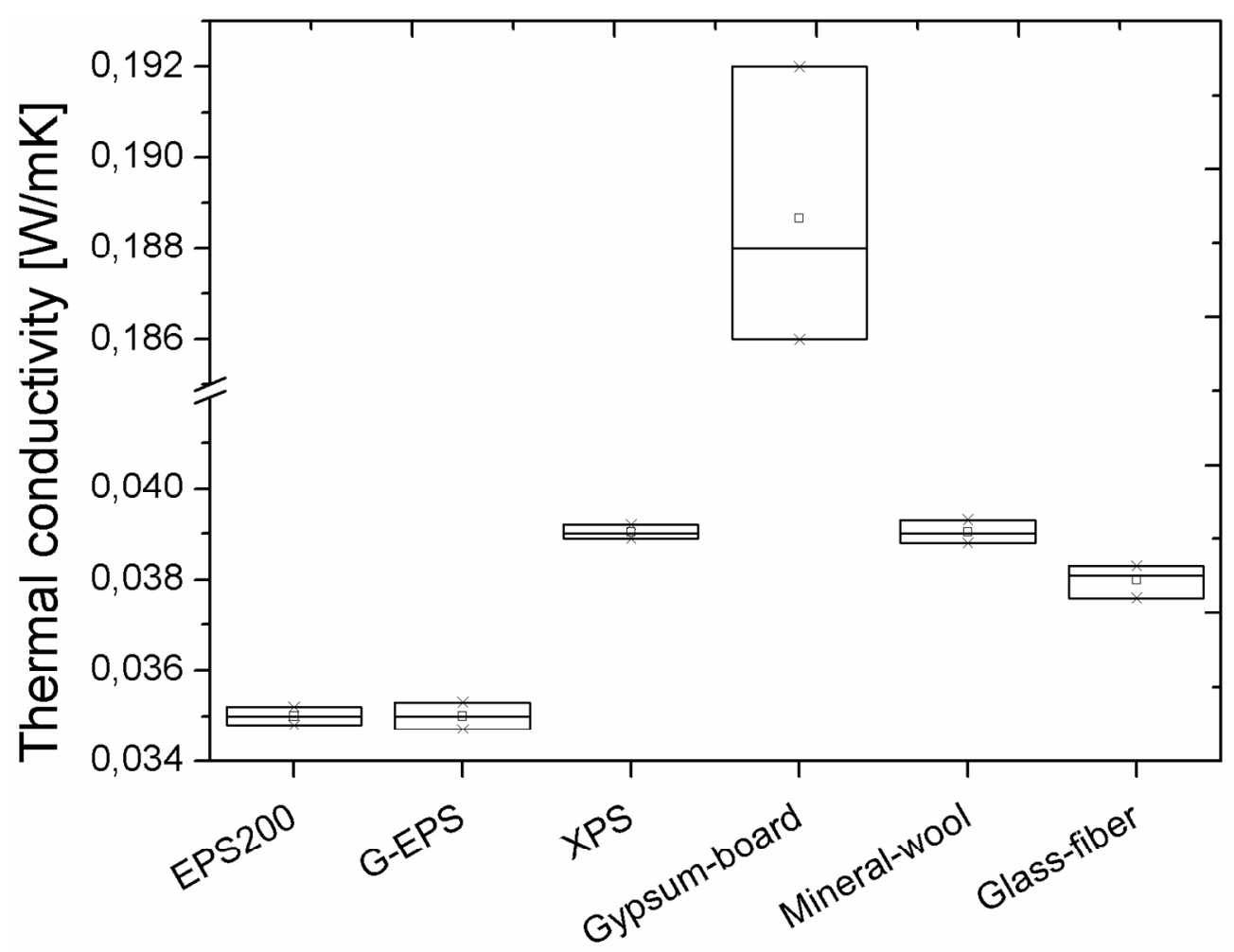

1. The measured thermal conductivities ploted by box chart method $287 \times 220 \mathrm{~mm}(150 \times 150 \mathrm{DPI})$

Review Copy Only. Not for distribution. 


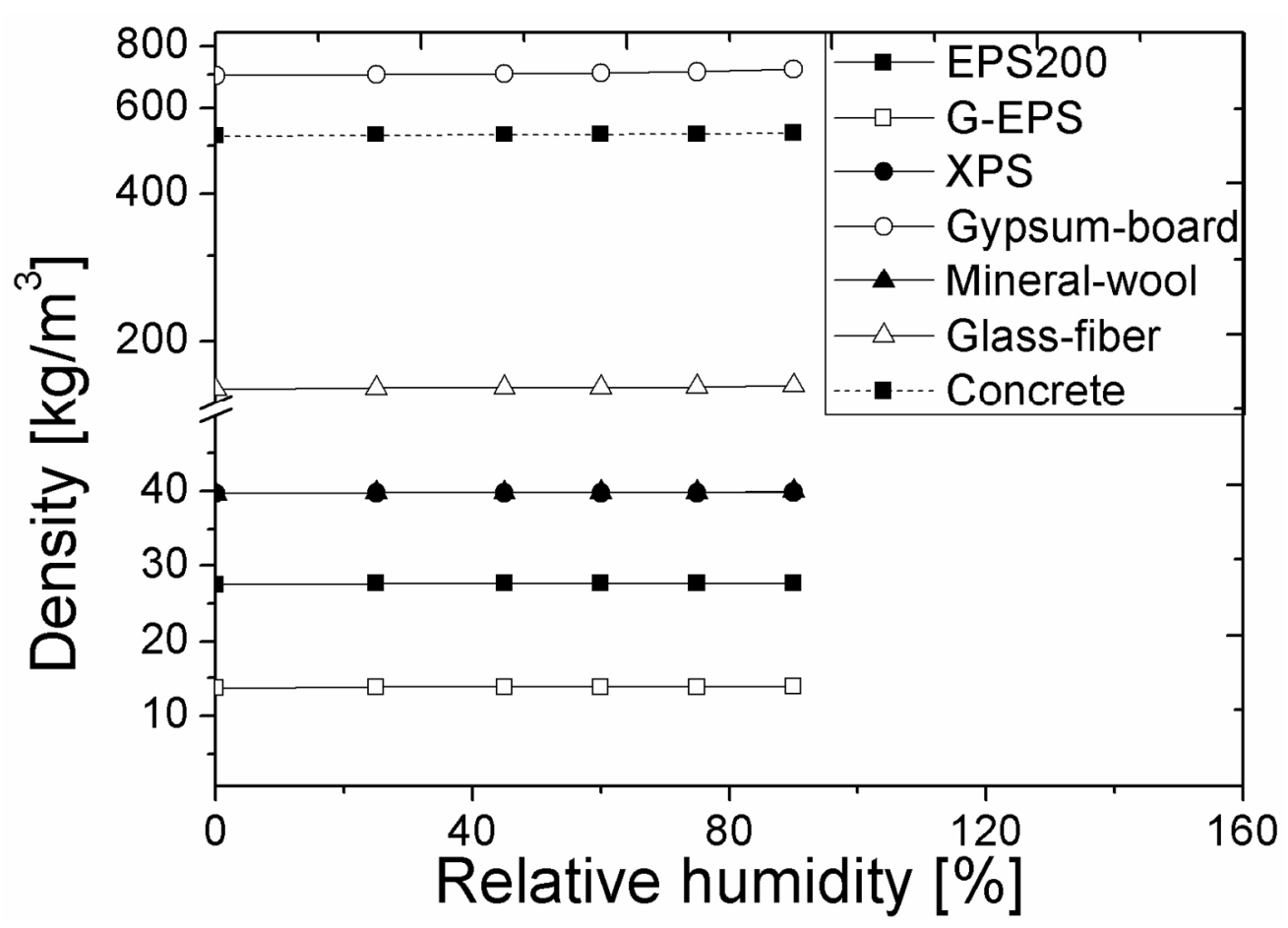

2. The moisture influenced changes of the density $287 \times 203 \mathrm{~mm}(150 \times 150 \mathrm{DPI})$

Review Copy Only. Not for distribution. 


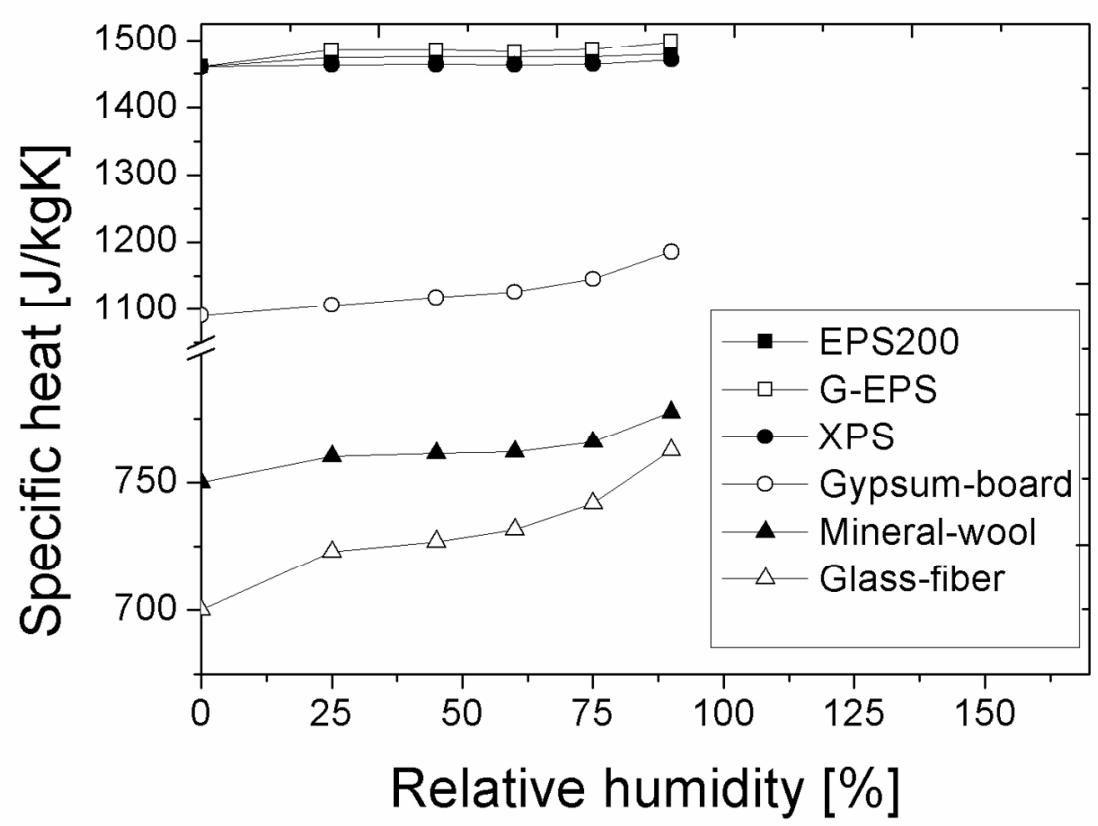

3. The moisture influenced changes of the specific heat $289 \times 201 \mathrm{~mm}(150 \times 150 \mathrm{DPI})$ 


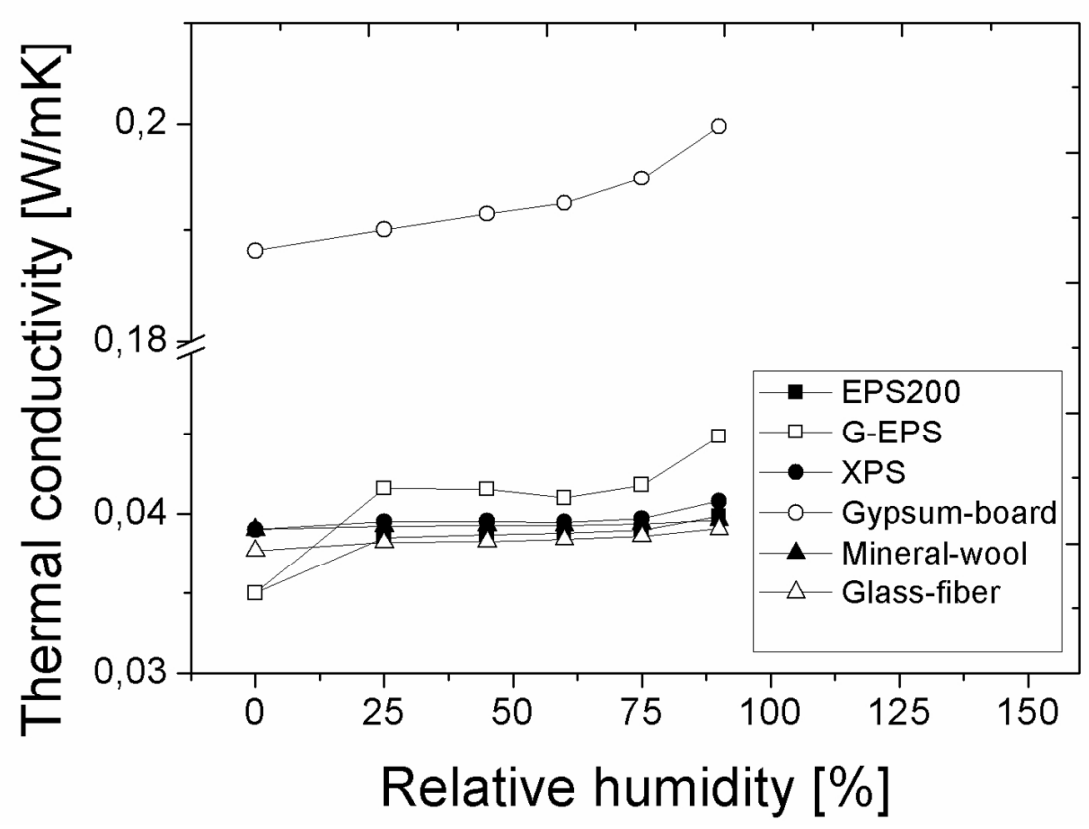

4. The moisture influenced changes of the thermal conductivity $289 \times 201 \mathrm{~mm}(150 \times 150 \mathrm{DPI})$ 


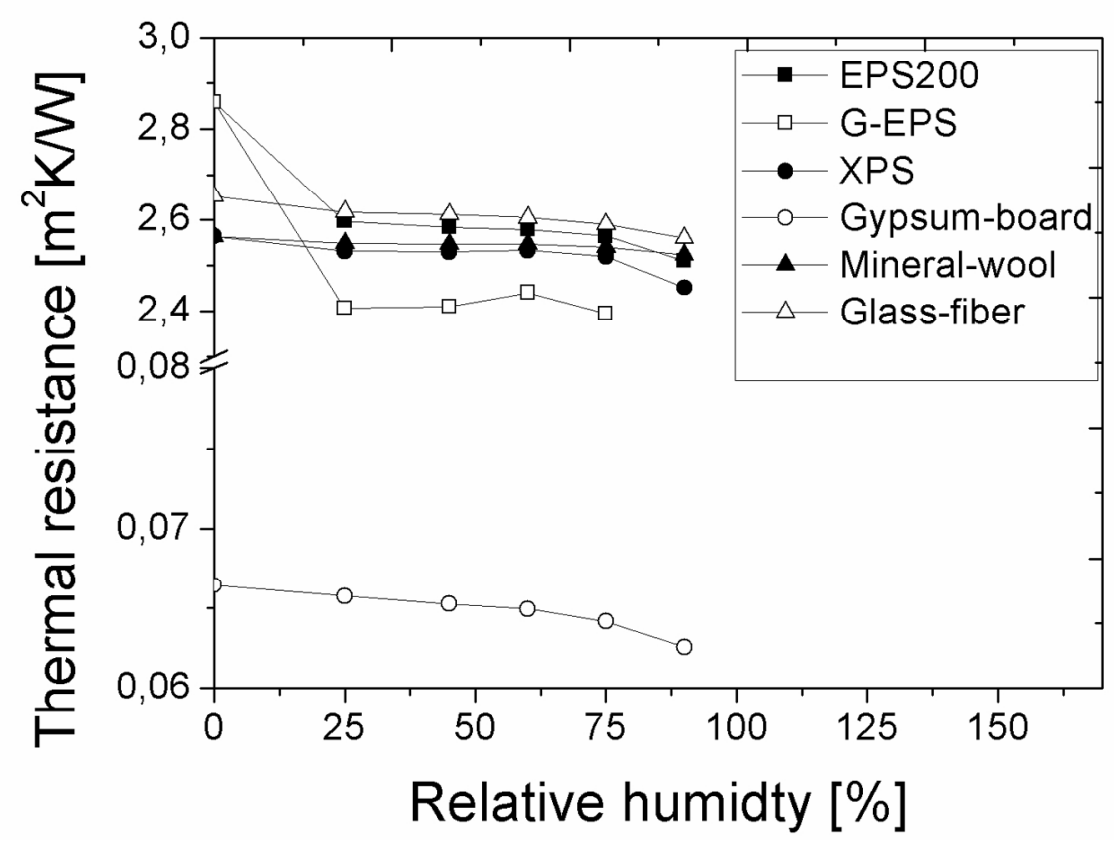

5. The moisture influenced changes of the thermal resistance $289 \times 201 \mathrm{~mm}(150 \times 150 \mathrm{DPI})$ 


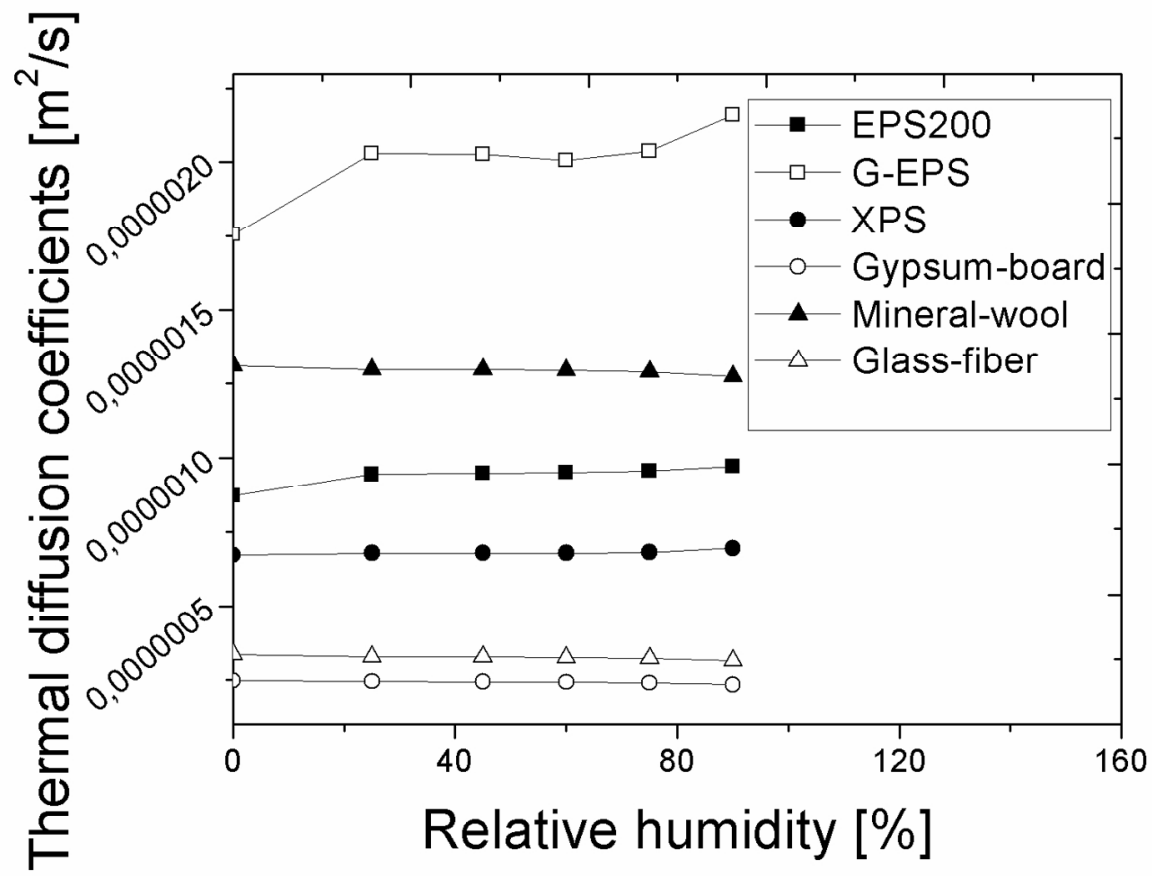

6. The moisture influenced changes of the thermal diffusion coefficients $289 \times 201 \mathrm{~mm}(150 \times 150 \mathrm{DPI})$

Review Copy Only. Not for distribution. 


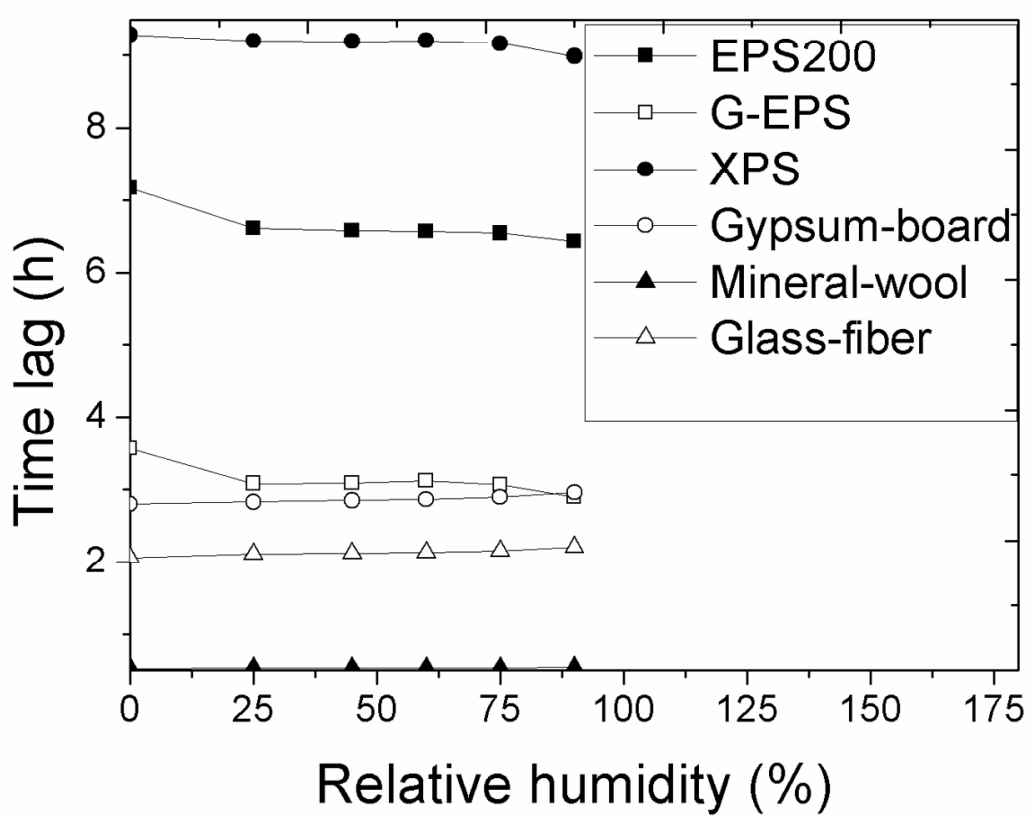

7. The moisture influenced changes of the time lag $289 \times 201 \mathrm{~mm}(150 \times 150 \mathrm{DPI})$

Review Copy Only. Not for distribution. 


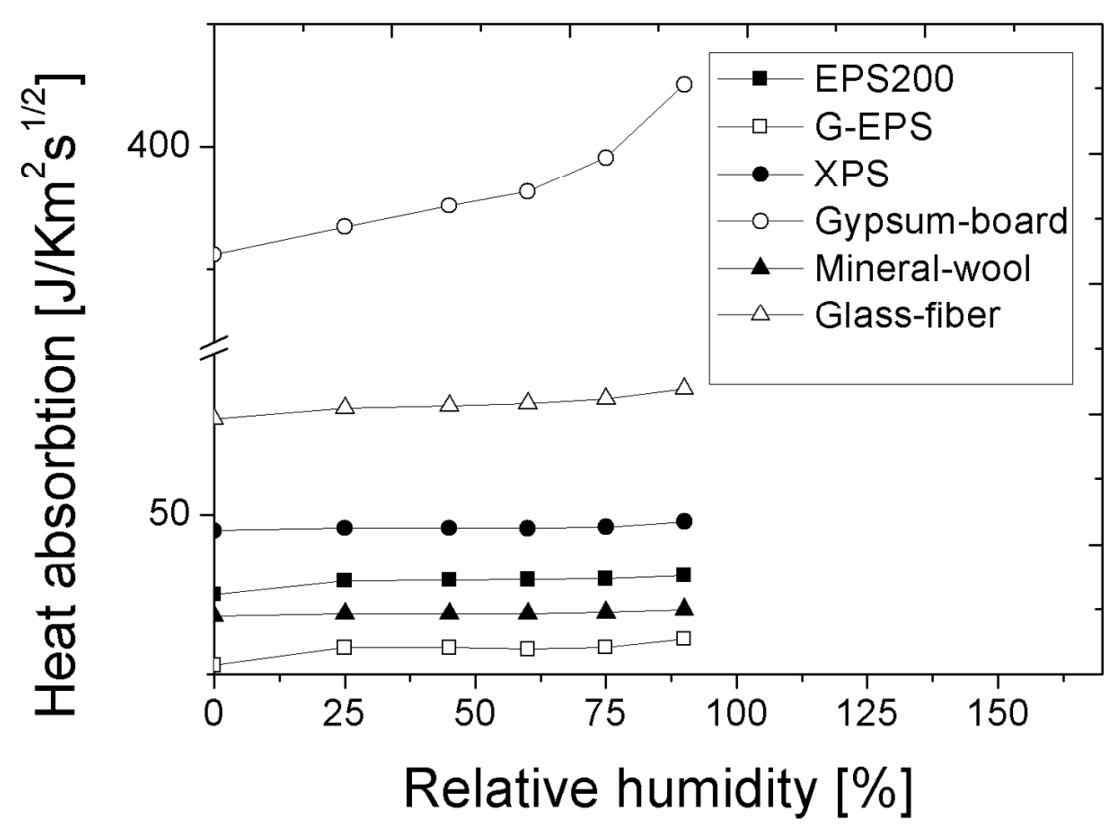

8. The moisture influenced changes of the heat absorption $289 \times 201 \mathrm{~mm}(150 \times 150 \mathrm{DPI})$ 


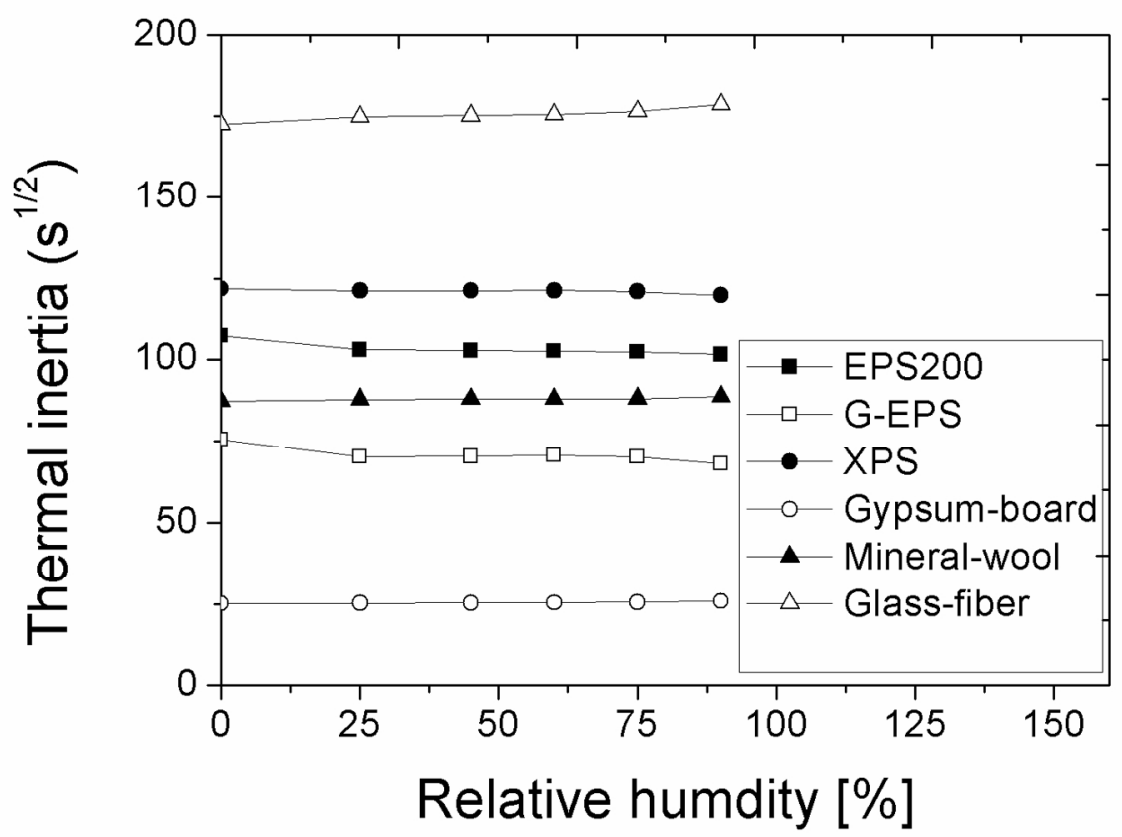

9. The moisture influenced changes of the thermal inertia $289 \times 201 \mathrm{~mm}(150 \times 150 \mathrm{DPI})$ 